\title{
Optimization Criteria for the Design of a Refrigerator Using Volume Consideration
}

\author{
Mohit Kumar Agarwal ${ }^{1}$, Manu Gupta ${ }^{2}$ \\ ${ }^{1}$ Mechanical Engineering, Arya College of Engineering \& IT, Delhi Road, Kukas, Jaipur-302028, India \\ ${ }^{2}$ Principal ,Mechanical Engineering, Arya College of Engineering\& IT, Delhi Road, Kukas, Jaipur-302028, India
}

\begin{abstract}
The global increasing demand for refrigeration in field of refrigeration air-conditioning, food preservation, vaccine storages, medical services, and cooling of electronic devices, led to production of more electricity and consequently more release of $\mathrm{CO}_{2}$ all over the world which it is contributing factor of global warming on climate change. Cylindrical refrigerator increase the useful volume also helps in space optimization and to get maximum volume at minimum total surface area. Therefore, proposed design refrigeration is greatly needed, particularly for developing countries where maximum volume and low maintenance are needed. Also provide good with save in energy.The objectives of this study is design and develop a working cylindrical refrigerator interior cooling volume of $444115008.2 \mathrm{~mm} \wedge 3$ that utilizes the Vapour compression refrigeration effect to refrigerate and maintain a selected temperature from $5{ }^{\circ} \mathrm{C}$ to $25^{\circ} \mathrm{C}$. The design reduces the wastage of energy also reduce stresses on the refrigerator body. We are study on the efficiency of the machine and on adjustable refrigerator body requirements, options available and the final design of ASFB refrigerator for application are presented.
\end{abstract}

Keywords: Cylindrical refrigerator, save space, maximum volume, vaccine storage

\section{Introduction}

Conventional refrigerators are having more total surface area as compare to ASFB Refrigerator design. Asfb utilize the maximum volume of the total volume. Also give sufficient increment in the total volume with respect to conventional design, it also provides extra space on shelves so that more volume can be used inside the body.

The glass door provide the clear view of the items hold in the refrigerator and sliding door help in easy access of refrigerator even at crowded kitchens and room .moving shelves, allowing user to easily access items and accessible to any area that are normally difficult in present design. It prove 360degree access to the shelves and shelves are capable of changing heights so that you can change the height of shelves as per demand of utensil. Water compartment grate help to prevent flowing of air and also help in regaining temperature after closing of the door. . There are less chances for cracks in a cylindrical refrigerator body than in a cubical body because of low stress consideration. Cylindrical design having less material weight as compared to convention design and also less number of welding joints are required.

\section{Features of Proposed Design}

I am proposing four changes in the present design,

1. Refrigerator Body Design

2. Shelves Design

3. Sliding Glass Door

4. Water Compartment/chamber

\subsection{Refrigerator Body Design}

To get particular volume we have to use bigger/large body or extra surface area, because of that there was extra mass on the body; this will be eliminated in proposed design.

\subsubsection{Increase in Overall-volume}

Proposed refrigerator is designed with concept for space optimization and to get maximum volume at minimum total surface area. Cylindrical shape is proposed for maximum use of volume in comparison to present design. On considering the refrigerator with dimension

Table 2.1: Calculation of proposed design

\begin{tabular}{|l|c|r|}
\hline \multicolumn{2}{|l|}{ Propesed design } & \\
\hline Radius 300 & Depth(H) & 1500 \\
\hline Circumference of circular base & 1884.955592 \\
\hline Area of Base & $\mathrm{pi}^{*} \mathrm{r}^{\wedge} 2$ & 282743.3388 \\
\hline Area of cylinder & $2^{*} \mathrm{pi}^{*} \mathrm{r}^{*} \mathrm{~h}$ & 2827433.388 \\
\hline Total surface area & $2 \mathrm{pir}^{\wedge} 2+2 \mathrm{pirh}$ & 3392920.066 \\
\hline Volume of Cylinder & $\mathrm{pi}^{*} \mathrm{r}^{\wedge} 2^{*} \mathrm{~h}$ & 424115008.2 \\
\hline
\end{tabular}

On considering with the present design having same total surface area and base area, we find the dimensions and compare 


\section{International Journal of Science and Research (IJSR) \\ ISSN (Online): 2319-7064}

Index Copernicus Value (2013): 6.14 | Impact Factor (2014): 5.611

Table 2.2: Volume consideration taking TSA and Area equal

\begin{tabular}{|c|c|c|c|}
\hline \multicolumn{4}{|c|}{ If the Base Area (Present design = Proposed design) } \\
\hline \multicolumn{2}{|c|}{ Propsed Design } & \multicolumn{2}{|c|}{ Present design } \\
\hline$r(\mathrm{~mm})$ & 300 & $1=\mathrm{b}(\mathrm{mm})$ & $?$ \\
\hline Area & 282743.3388 & Area & 282743.3388 \\
\hline \multicolumn{3}{|c|}{ Leng th of the rectang $l e=\sqrt{\text { pir }} 2$} & 531.7361553 \\
\hline \multicolumn{2}{|c|}{ Width of rectangle $=\sqrt{\text { pir }} 2$} & & 531.7361553 \\
\hline \multicolumn{4}{|c|}{ If Total surface Area (Pre design = Pro design) } \\
\hline \multicolumn{2}{|c|}{ Propsed Design } & \multicolumn{2}{|c|}{ Present design } \\
\hline $\mathrm{h}(\mathrm{mm})$ & 1500 & $\mathrm{~h}$ & $?$ \\
\hline TSA & 3392920.066 & TSA & 3392920.066 \\
\hline \multicolumn{2}{|c|}{ Hight of cuboidal design } & & 1329.340388 \\
\hline \multirow{2}{*}{\multicolumn{4}{|c|}{ Then as per dimensions the area and volume are }} \\
\hline & & & \\
\hline \multicolumn{2}{|c|}{ Circumference of rectangle } & & 2126.944621 \\
\hline \multicolumn{2}{|c|}{ Volume of Cuboidal } & & 375862139.8 \\
\hline \multicolumn{4}{|c|}{ comparing Volume inPresent design vs pro design } \\
\hline \multicolumn{2}{|c|}{ Proposed Design } & \multicolumn{2}{|c|}{ Present design } \\
\hline Volume & 424115008.2 & Volume & 375862139.8 \\
\hline \multicolumn{2}{|c|}{ Increase in volume } & & 48252868.45 \\
\hline \multicolumn{2}{|c|}{$\%$ increase in volume } & & 12.8379 \\
\hline
\end{tabular}

On comparing both the arrangements we find an increase of $\mathbf{1 2 . 8 4 \%}$ in proposed design volume as compared to present design.

\subsubsection{Increase in Useful Volume as compared to Total}

Volume on part wise consideration we find the useful volumein proposed design.
Table 2.3: Useful Volume calculation taking TSA and Area equal

\begin{tabular}{|c|c|c|c|}
\hline \multicolumn{2}{|c|}{ Proposed Design } & & \\
\hline \multicolumn{4}{|c|}{ Cooling unit (CU) } \\
\hline Radius(n & 300 & Depth (mm) & 300 \\
\hline \multicolumn{2}{|c|}{ Volume (V) of CU } & 84823001.65 & \\
\hline \multicolumn{2}{|c|}{ Not useful V(Nuv) } & 84823001.65 & \\
\hline \multicolumn{2}{|c|}{ Us eful Volume } & 0 & \\
\hline \multicolumn{4}{|c|}{ Ice Chamber (IC) } \\
\hline Radius & 300 & Depth & 298.5 \\
\hline \multicolumn{2}{|c|}{ Volume of IC } & 84398886.64 & \\
\hline \multicolumn{2}{|c|}{ Us eful Volume } & 84398886.64 & \\
\hline Nuv & & 0 & \\
\hline \multicolumn{4}{|c|}{ Refrigeration Chamber } \\
\hline Radius & 300 & Depth & 779.71 \\
\hline \multicolumn{2}{|c|}{ Volume of RC } & 220457808.7 & \\
\hline \multicolumn{2}{|c|}{ Nuv 3-shelves } & 6561530.416 & \\
\hline \multicolumn{2}{|c|}{ Nuv 9- bearings } & 300591.5121 & \\
\hline \multicolumn{2}{|c|}{ Us eful Volume } & 213595686.8 & \\
\hline \multicolumn{4}{|c|}{ Water Chmber } \\
\hline Radius & 300 & Depth & 119.9975 \\
\hline \multicolumn{2}{|c|}{ Total volume } & 33928493.8 & \\
\hline Nuv & & 168939.1449 & \\
\hline \multicolumn{2}{|c|}{\begin{tabular}{|l} 
Us eful volume \\
\end{tabular}} & 33759554.66 & \\
\hline \multicolumn{4}{|c|}{ 3- partition at IC,CU and RC } \\
\hline Radius & 300 & Depth & 0.5975 \\
\hline Volume & & 506817.4348 & \\
\hline Nuv & & 506817.4348 & \\
\hline Uv & & 0 & \\
\hline \multicolumn{4}{|c|}{ Total us eful volume with respect to total volume } \\
\hline \multicolumn{2}{|c|}{ Total volume } & 424115008.2 & \\
\hline \multicolumn{2}{|c|}{ Us eful volume } & 331754128.1 & \\
\hline \multicolumn{2}{|c|}{ \%us eful volume } & 78.22268056 & $\%$ \\
\hline
\end{tabular}

On calculation we found that $\mathbf{7 8 . 2 2} \%$ volume of refrigerator is useful in proposed design. Volume on part wise consideration we find the useful volume in present design, 


\section{International Journal of Science and Research (IJSR)}

ISSN (Online): 2319-7064

Index Copernicus Value (2013): 6.14 | Impact Factor (2014): 5.611

Table 2.4 Useful Volume calculation taking TSA and Area equal

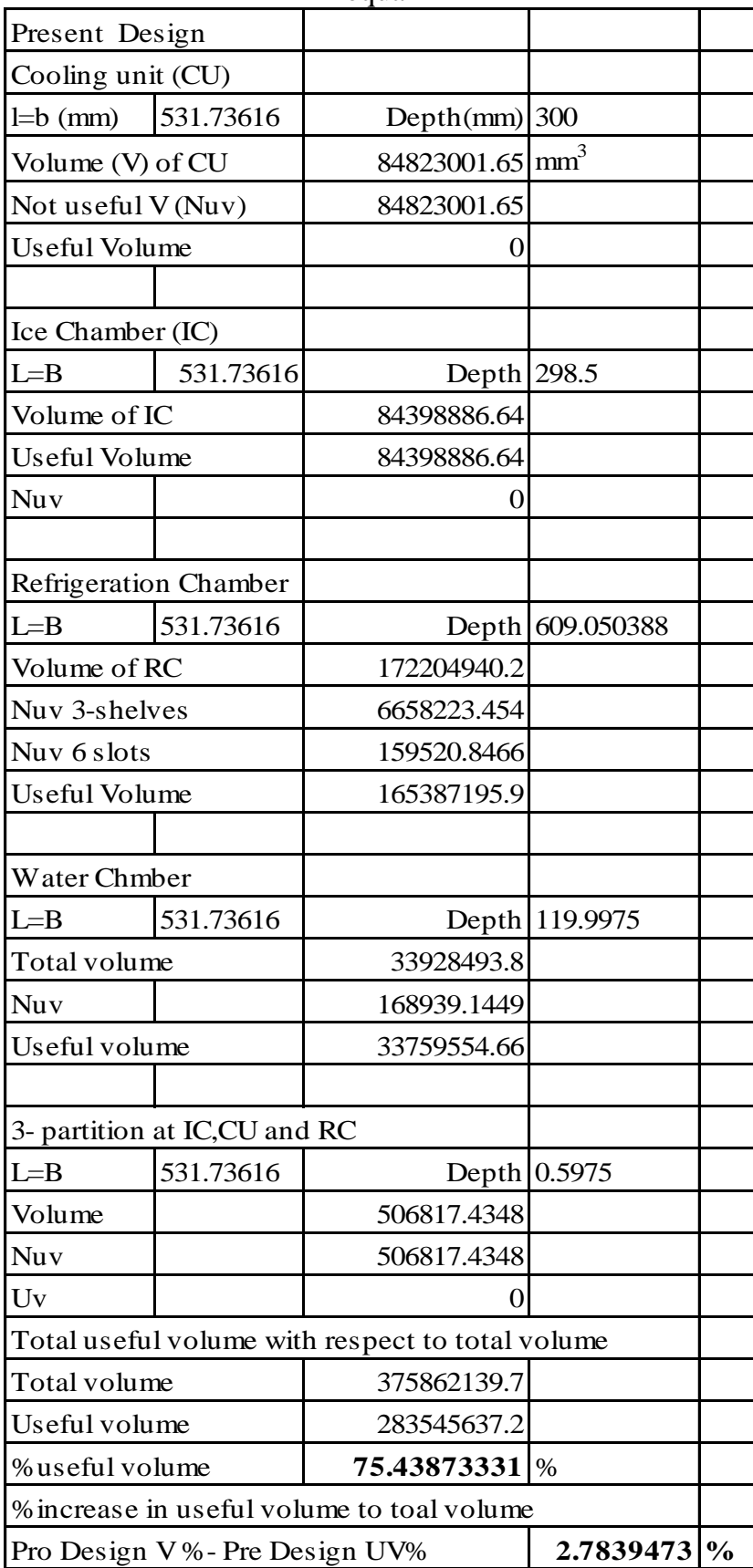

On calculation we found that $\mathbf{7 5 . 4 3 \%}$ volume of refrigerator is useful in Present design. And we get increase of $\mathbf{2 . 7 8 \%}$ useful volume to the total volume in proposed design.

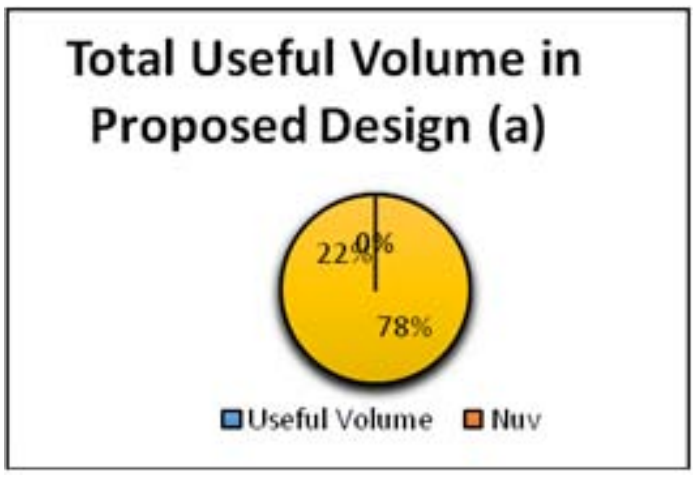

Total Useful Volume in Present Design(b)

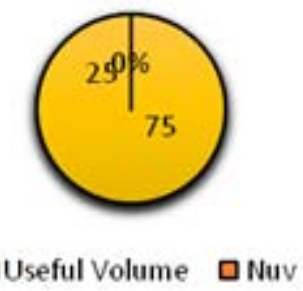

Figure 1: Total useful Volume (in percentage)

\subsubsection{Material saving and easy production}

The Production of proposed design refrigerator is easy compared to present design. Less number of welding joints is required in elliptical or cylindrical vessels than cubical ones.

On comparing the metal use $\left(.01 \mathrm{~g} / \mathrm{mm}^{2}\right)$ we find that

Table 2.5: Calculation Mass of Material by calculation TSAat equal $\mathrm{V}$

\begin{tabular}{|l|c|r|r|}
\hline \multicolumn{2}{|l|}{ Present design } & \multicolumn{2}{r|}{ Proposed design } \\
\hline $1(\mathrm{~mm})$ & 531.7361553 & $\mathrm{r}$ & 300 \\
\hline $\mathrm{b}(\mathrm{mm})$ & 531.7361553 & $\mathrm{~h}$ & 1500 \\
\hline $\mathrm{h}(\mathrm{mm})$ & 1500 & & \\
\hline TSA & 3755903.609 & TSA & 3392920.1 \\
\hline & & & \\
\hline Total surface area difference & 362983.54 & \\
\hline \% increase in TSA & $\mathbf{1 0 . 6 9 8 2 6}$ & $\%$ \\
\hline
\end{tabular}

Total surface area of square base is more than total surface area of circular base. Let the mass of metal is $.01 \mathrm{~g} / \mathrm{mm}^{2}$, then mass of material decreased by $\mathbf{1 0 . 6 9 \%}$ in proposed design.

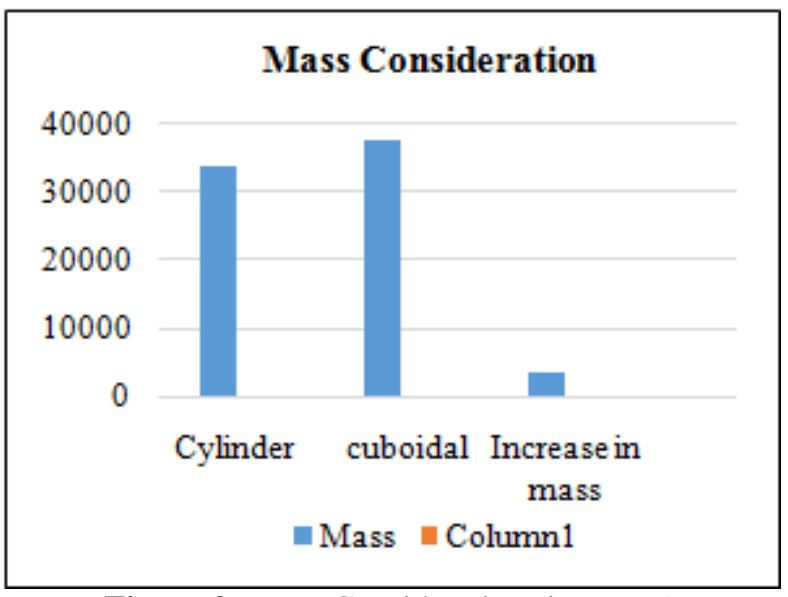

Figure 2: Mass Consideration (in grams)

\subsubsection{Stress at Corners}

We know that the stress at the point, in a section is directly proportional to its distance from the neutral axis. Therefore 


\section{International Journal of Science and Research (IJSR) \\ ISSN (Online): 2319-7064}

Index Copernicus Value (2013): 6.14 | Impact Factor (2014): 5.611

maximum stress in a section will be occur in the extreme fiber of the section.

Table 2.6 Calculation of Distance from neutral axis

\begin{tabular}{|l|r|l|l|l|}
\hline \multicolumn{2}{|l|}{ present design } & & \multicolumn{2}{l|}{ Proposed design } \\
\hline $\mathrm{l}$ & 600 & & $\mathrm{r}$ & 300 \\
\hline $\mathrm{b}$ & 600 & & & \\
\hline \multicolumn{2}{|l|}{ length of diagonal } & & \multicolumn{2}{|l|}{ Lenth of diagonal } \\
\hline $\mathrm{l}$ & 848.52814 & & 1 & 600 \\
\hline
\end{tabular}

As we can see that in rectangle the corner is far then in circle or in cylinder. Rectangular type of cross section are having problem of stress concentration. When carrying load, the stress acting at a corner is more than the stress acting on the sides. Because of this, the stress concentrates more at the corners. And because of this there are more chances of a body to break and leakage if they are made rectangular or cubical. There are less chances for cracks in a cylindrical body than in a cubical tank. You can imagine for the same length of axis, cylindrical cross section have more perimeter than rectangular shape. This makes the weight to be distributed over more area thus reducing pressure or load on vessel. Thus instead of a simple cylindrical vessel, ones give us more volume.

\subsection{Shelves Design}

Handling is difficult in present shelves, also our jug/utensils are usually in cylindrical shape so the volume at the edges of the shelve waste and remain unoccupied.

\subsubsection{Increase in Useful volume at shelves}

On comparing the no of maximum bottle that can arrange on the shelves we found

Table 2.7: Calculation of Useful volume on shelves

\begin{tabular}{|c|c|c|c|}
\hline \multicolumn{3}{|c|}{ Taking bottle of $75 \mathrm{~mm}$ Diameter } & \\
\hline \multicolumn{2}{|c|}{ Proposed design } & \multicolumn{2}{|c|}{ Present design } \\
\hline \multirow[t]{2}{*}{ Shelves (r) } & 295 & Shelves L & 531.7361553 \\
\hline & & Shelves B & 521.7361553 \\
\hline Area & 273397.1007 & Area & 277425.9773 \\
\hline Maxbottle & 52 & Max Bottles & 49 \\
\hline \multicolumn{3}{|c|}{ Useful Hight for both the Design let } & 755.71 \\
\hline UVpro & 173608474.5 & UV pre & 163592600.9 \\
\hline$\% U V$ & 84.02757828 & \%UVpre & 78.02995628 \\
\hline \multicolumn{3}{|c|}{ Volume \% more used by Proposed design } & 5.998 \\
\hline
\end{tabular}

On comparing the useful volume by shelves in both the design, we find that proposed design use $\mathbf{5 . 9 9 \%}$ more volume then the present design.

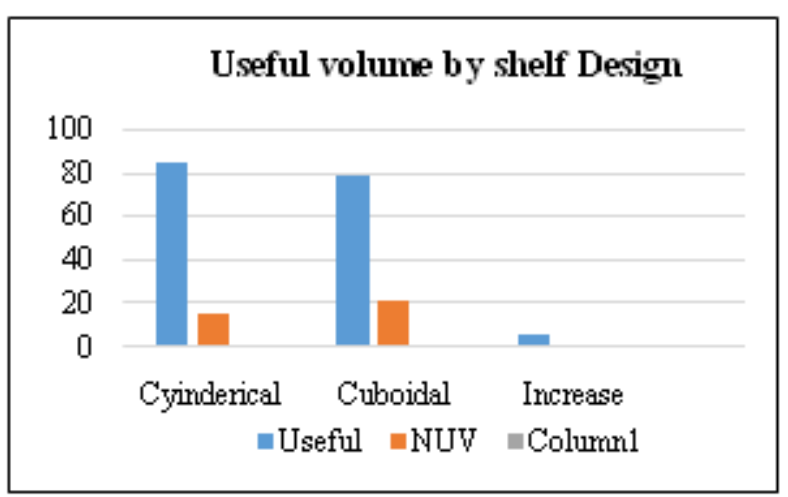

Figure 3: Total useful Volume in shelves (in percentage)

\subsubsection{Adjustable Shelves / Shelf}

The Proposed refrigerator concept contains the moving shelves that can rotates, allowing user to easily access items and accessible to any area that are normally difficult in present design. With rotating shelves that spin your food right into a front position as needed. In addition, the shelves are capable of changing heights or say can flips up and down easily so that adjusting of things gets simpler by lowering them or raising them as per need. Adjustable shelves also collapse to fit your space when you collapse the fridge body to save the wastage space and to reducing your energy use

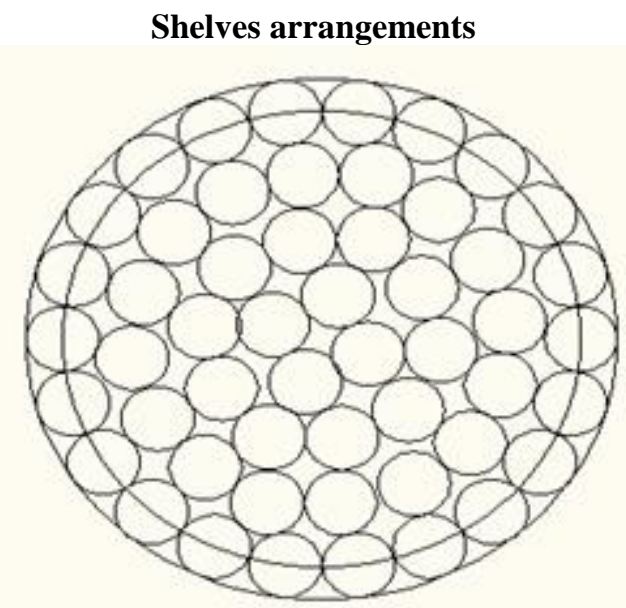

Bottles arrangement in Circular Shelves (52)

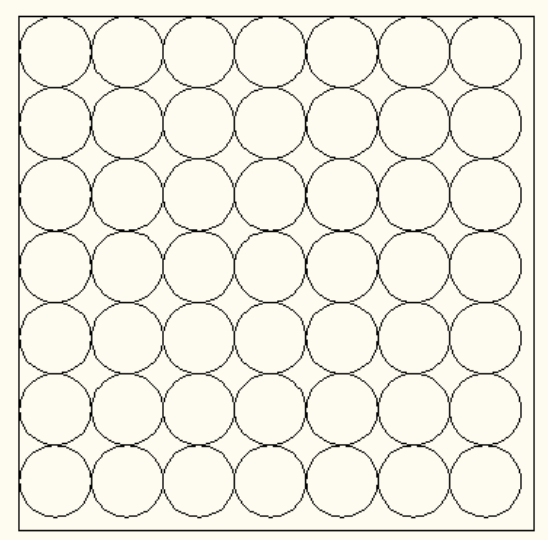

Bottles arrangement in Circular Shelves (52)

Figure 4: Shelves arrangement 


\section{International Journal of Science and Research (IJSR) \\ ISSN (Online): 2319-7064 \\ Index Copernicus Value (2013): 6.14 | Impact Factor (2014): 5.611}

\subsection{Sliding Glass Door}

Proposed refrigerator is designed with concept for space optimization in crowded room and to save energy. The refrigerator with glass door that lets you see what your fridge holds. Outer door will be a made up of clear frosted glass. You will get to know whether the fridge is on without opening the door. The light switch will on and off when you open the door. The glass door slide into the cylinder foot print and save space to access the refrigerator. Space required accessing the refrigerator in present fridge

Table 2.8 calculation volume use to access the Door

\begin{tabular}{|l|r|r|r|}
\hline \multicolumn{2}{|c|}{ present design } & \multicolumn{2}{|c|}{ Proposed design } \\
\hline 1 & 531.7361553 & $\mathrm{R}$ & 340 \\
\hline $\mathrm{w}$ & 531.7361553 & $\mathrm{t}$ & $\mathrm{S}$ \\
\hline $\mathrm{H}$ & 1329.340388 & $\mathrm{~h}$ & 1500 \\
\hline $\mathrm{V}\left(\mathrm{mm}^{3)}\right.$ & 295201434.3 & $\mathrm{~V}$ & 12096000 \\
\hline & & & \\
\hline \multicolumn{2}{|c|}{ Difference in volume } & 283105434.3 & \\
\hline \multicolumn{2}{|c|}{$\%$ save in volume } & $\mathbf{2 3 4 0 . 5}$ & $\%$ \\
\hline
\end{tabular}

The fridge not only looks great but also save about $\mathbf{2 3 4 0 . 5 \%}$ of volume to access the door. Also save energy with its ergonomic design. Present refrigerator use 2304 (proposed design door) volume at doors.

\subsection{Water Compartment/Chamber}

The refrigerator is designed keeping in view the energy that get wasted with the opening of the door for water bottles. The fridge is designed to minimize the flow of cool air outside. Water compartment great help to prevent flowing of air and also help in regaining temperature after closing of the door.

It is divided in sections, where the bottom section is for ice chamber and top section is cooled using normal or vapor compress refrigeration. Middle section is made up of heat insulating material with 3 adjustable shelves to keep your food / eatables cool.

Water is supplied to refrigerator by direct connection from RO of any other reservoir will store at the top of the compartment.

Also help in regaining the required temperature in the refrigerator through convection and transfer cooling from top toward bottom within effect of gravity. It will not use extra energy in cooling.

\section{Scope for the Future Research}

We are study on addition for this design .That design will collapse to fit the space and save energy as well. In this fridge you can increase the volume and reduce the volume as per our needs, it will save energy also reduce the cooling time so that we can attain the required temperature in less time. When there is no eatable item or less food inside the fridge. You can collapse it thereby saving upon energy and space. We may use sliding mechanism to collapse the body of the refrigerator. Also study on the efficiency of the machine

\section{Conclusion}

1) Increase of $\mathbf{1 2 . 8 4 \%}$ in total volume in proposed design as compared to present design.

2) Increase of $\mathbf{2 . 7 8 \%}$ in useful volume to the total volume in proposed design.

3) Mass of material used for making body decreased by $\mathbf{1 0 . 6 9 \%}$ in proposed design.

4) Stress concentrates and leakage reduce at corners.

5) Useful volume at shelves increased by $\mathbf{5 . 9 9 \%}$ in proposed design.

6) Shelves can rotate, allowing user to easily access items and accessible to any area.

7) Shelves are capable of changing heights or say can flips up and down easily.

8) Save about $\mathbf{2 3 4 0 . 5 \%}$ of volume to access the door.

9) Water compartment prevent flowing of air and also help in regaining temperature after closing of the door.

\section{References}

[1] http://drprem.com/home/15-uber-cool-refrigeratorconcepts-to-put-your-standard-fridge-to-shame

[2] http://www.yankodesign.com/2011/03/03/open-sesame/

[3] http://machinedesign.com/archive/industrys-bestdesigns-newmillennium

[4] http://www.slipperybrick.com/2008/10/electrolux-softrefrigerator-concept/

[5] http://www.samsung.com/in/award/3050BMF/discover/ more-space-five.html

[6] http://itechfuture.com/concept-refrigerator-of-futureaxon/

[7] https://www.behance.net/gallery/11782249/Refrigerator -Concept-Animation

\section{Author Profile}

Mohit Kumar Agarwal is a B-tech student in mechanical engineer at Arya College of engineering and IT,

Manu Gupta is a Principal of ACEIT, PHD in designing and Mechanical engineer. 